\title{
Evaluating Building Energy Code Compliance and Savings Potential through Large Scale Simulation with Models Inferred by Field Data
}

\author{
Yulong Xie ${ }^{1}$, Mark Halverson ${ }^{1}$, Rosemarie Bartlett ${ }^{1}$, Yan Chen $^{1}$, Michael Rosenberg ${ }^{1}$, Todd \\ Taylor $^{1}$, Jeremiah Williams ${ }^{2}$ \\ ${ }^{1}$ Pacific Northwest National Laboratory, Richland, Washington, USA \\ ${ }^{2}$ U.S. Department of Energy, Washington D.C., USA
}

\begin{abstract}
Building energy code compliance is the critical link between the efficiency specified in energy codes and actual energy savings. In a recent research study that evaluated the current status and identified gaps in code compliance in U.S. states, we proposed a novel methodology, based on large scale building energy simulation inferred by limited field data, to assess performance of a large population of homes. This methodology addresses two issues that impact existing methodologies: a lack of energy performance metrics and the cost of field surveys. This paper presents the methodology and the results of this study.
\end{abstract}

\section{Introduction}

In the U.S., building energy use accounted for $40 \%$ of total energy consumption and $75 \%$ of total electricity consumption in 2016 (U.S. EIA, 2017). As a costeffective way for reducing energy consumption, building energy codes, which govern building construction to meet minimum energy requirements, have been established in the U.S. and many other countries. Code compliance is a critical link between the energy efficiency prescribed in the energy codes and the actual energy savings. The energy savings from stringent energy codes cannot be delivered unless new buildings are constructed to comply with the code. In the U.S., state legislatures, local jurisdictions, utility companies and energy efficiency program administrators are interested in knowing the current status of code compliance and the energy saving potential in their jurisdictions. They rely on such information for policymaking, targeted training and outreach activities to improve the code compliance, resource planning, and payback of investments (Lee and Groshans, 2013).

Historically, most building energy code compliance studies do not directly estimate energy savings. Instead, they rely on a compliance rate, which is calculated as the percentage of the individual code items that are in compliance. However, such a compliance rate does not correspond directly to energy consumption, making it difficult to estimate potential energy savings (Bartlett et al., 2016; PNNL, 2010). On the other hand, code compliance evaluation cannot be completed without collecting data through site surveys. These surveys are expensive and it is difficult to collect complete and sufficient information for engineering calculations or computer simulations, especially in a large scale code compliance exercise for a U.S. state.

There is an increasing trend to use building energy performance as a metric and building energy simulation as tools for the code compliance evaluation (Rosenberg et al., 2016; Storm et al., 2016). Building simulation has been widely used to support the analysis of building performance for a variety of research and practical purposes. Compared to in-situ building experiments, building energy simulation provides a numerical experiment with a relatively fast, low-cost, and controllable environment to investigate the impact of design options and technologies on a building's energy performance. There are many sophisticated building energy simulation tools and EnergyPlus (Crawley et al., 2001) is one that has been used widely for the development of building energy codes in the U.S. and was thus chosen for the evaluation of code compliance in this study.

There are challenges to using building simulation for evaluating code compliance and having the complete model inputs is the most difficult one. When building energy simulation is used to compare individual building design options and technologies or evaluate retrofit measures, the detailed model inputs could be derived from building design documents, building permits, or from actual observations of individual buildings under retrofit. When building energy simulation is used to support energy code development or evaluate energy efficiency measures for a population of buildings, prototypical building models are generally used (Thornton et al., 2011; Deru et al., 2011; Reinhart and Davila, 2016). The characteristics of the prototypical buildings are known as well as their operations and control schemes (Wang et al., 2013; Fernandez et al., 2017). However, this is not the case when applying a building simulation tool for the evaluation of code compliance.

In the evaluation of code compliance, the code requirements are known and site visits are the only way to truly confirm code compliance. However, the long timeline and complexity of building construction make it impossible to observe all code items from a single site visit. Multiple site visits during different construction phases not only increases the cost but also introduces biases on the data collection due to the awareness of the builder of the upcoming visits. The builder's practice may be altered by knowing there are follow-up compliance 
assessments in the future. All these lead to the approach that field visits are only conducted on a small sample of buildings and not all code items will be collected from each building visited.

Since comprehensive field surveys for the energy simulation of individual buildings becomes impractical in evaluating code compliance at the scale of an entire state due to the large volume, long timelines, and complexity of building construction, we proposed a novel modelling framework to leverage limited field data collection with large scale simulation. The framework encompasses all aspects of conducting a residential energy code field study in single-family homes, including sampling homes under construction, data collection during a site visit, and the subsequent simulation and analysis. The entire study consists of three phases, a Phase I baseline study to evaluate the current state of energy use in typical residential homes in the state and to identify specific code requirements that present opportunities for improved compliance, a Phase II for education, training and outreach activities aimed at improving compliance for those code requirements identified in Phase I, and a Phase III for a follow-up field data collection and analysis to evaluate the effectiveness of Phase II. The developed framework has already been applied to the data collection and analysis of Phase I as reported in Xie et al., 2018. This paper focuses on the data collection and analysis of Phase III as well as a comparison between Phase I and III.

The remainder of this paper is organized as follows: the Background section provides a background of the three phases of this study. The Methodology section briefly introduces the aspects of the framework that have otherwise been described and applied in Phase I (Xie et al., 2018) with a focus on Phase III. The Results section and the Discussion and Conclusion sections present the Phase III results for four states that have completed the data collection and analysis, as well as the comparison between Phase III and Phase I.

\section{Background}

A multi-year residential energy code field study was initiated by the United States Department of Energy (U.S. DOE) in 2015. The goals of the study were to (1) establish a framework to evaluate the current status of code compliance and quantify code-related energy savings opportunities in single-family residential construction, and (2) test whether compliance could be improved through energy code education, training \& outreach activities. Eight U.S. states, including Alabama, Arkansas, Georgia, Kentucky, Maryland, North Carolina, Pennsylvania and Texas, participated in the study by responding to the U.S. DOE Funding Opportunity Announcement (FOA), "Strategies to Increase Residential Energy Code Compliance Rates and Measure Results" (FOA, 2014; Williams et al., 2018).

Phase I of the study develops a framework for evaluating residential building code compliance. The framework includes plans for site surveys, protocols for data collection, and a methodology for data analysis including EnergyPlus simulation. The analysis methodology uses building energy simulation to replace the historic compliance rate approach. Prototype building models are used for the analysis. Limited field data is collected and bootstrap sampling (Hesterberg, 2015) is applied to generate inputs for a large number of building models on which EnergyPlus simulation is conducted. The developed methodology has previously been applied to field data collected during Phase I in the eight pilot states funded by the FOA. The analysis identified gaps in code compliance, and those to-be-improved code items became targets for training, education and outreach activities. The energy saving potential of to-be-improved code items are also estimated (Xie et al., 2018).

Following Phase I, the participating states spent two years implementing a variety of intervention strategies, focused on the to-be-improved code items identified in Phase I, using education, training and outreach activities aimed at improving compliance.

The Phase III follow-up field data collection and analysis are based on the same framework developed and applied in Phase I, aiming to evaluate the effectiveness of the education, training and outreach activities of Phase II. At the time of writing, four out of eight states have completed Phase III data collection and analysis.

Additionally, ten other states used the methodology to complete single-phase studies, with U.S. DOE providing the technical analyses through the Pacific Northwest National Laboratory. This paper focuses on results of the pilot states from the original three-phase study.

\section{Methodology}

The framework and analysis methodology developed in Phase I is described in Xie et al. 2018. For completeness, a brief introduction has been included in this section.

\section{Key Code Items}

Building energy codes regulate a large number of building characteristics. In this study, the methodology (U.S. DOE, 2018) evaluates seven key code items shown in Table 1, which is a subset of code items identified through simulation and analysis as having the largest direct impact on residential energy consumption.

\section{Sample Size and Data Collection}

A statistical analysis was conducted based on sensitivity analysis employing whole building energy simulation to investigate the impact of key code items. A sample size of 63 was established as the minimum sample size to identify the desired building energy usage difference (Bartlett et al., 2018). A proportional random sampling approach was used to design the sample plan based on the average of the three years of Census Bureau permit data (U.S. Census Bureau, 2017). A data collection team contacted each jurisdiction identified in the sample plan to obtain a list of homes at various stages of construction within the jurisdictions. Homes were selected at random for data collection (Halverson et al., 2015; Bartlett et al., 2018). For each selected home, a single site visit was planned to avoid biases associated with multiple visits. 
Table 1: Key Code Items.

\begin{tabular}{|l|l|}
\hline \multicolumn{1}{|c|}{$\begin{array}{c}\text { Key Code } \\
\text { Requirement }\end{array}$} & \multicolumn{1}{c|}{ Metric } \\
\hline Envelope Tightness & $\begin{array}{l}\text { Air changes per hour at } 50 \\
\text { Pascals }\end{array}$ \\
\hline Duct Leakage & $\begin{array}{l}\text { Cubic meter per second } / 100 \mathrm{~m}^{2} \\
\text { conditioned floor area at } 25 \\
\text { Pascals }\end{array}$ \\
\hline Wall Insulation & R-value $\left(\mathrm{m}^{2}-\mathrm{K} / \mathrm{W}\right)$ \\
\hline Ceiling Insulation & R-value $\left(\mathrm{m}^{2}-\mathrm{K} / \mathrm{W}\right)$ \\
\hline $\begin{array}{l}\text { Floor or Foundation } \\
\text { Insulation }\end{array}$ & R-value $\left(\mathrm{m}^{2}-\mathrm{K} / \mathrm{W}\right)$ \\
\hline Window Efficiency & $\begin{array}{l}\text { Window } \mathrm{U} \text { factor }\left(\mathrm{W} / \mathrm{m}^{2}-\mathrm{K}\right) \text { and } \\
\text { Solar Heat Gain Coefficient } \\
\text { (SHGC) }\end{array}$ \\
\hline $\begin{array}{l}\text { High Efficacy } \\
\text { Lighting }\end{array}$ & $\begin{array}{l}\text { Percentage of all permanently } \\
\text { installed lamps or luminaires }\end{array}$ \\
\hline
\end{tabular}

It can be seen from Table 2 that the single site-visit principle necessitated visits to 133-249 homes in Phase I and 121-185 homes in Phase III to obtain at least 63 samples for all key items, depending on the state. As shown in Table 2, the number of homes visited during field survey consists of a small sample of the estimated construction permits issued in each state. The data collected for the eight states during Phase I are publicly available at the residential field study page on the U.S. DOE's Building Energy Code Program's website (https://www.energycodes.gov/compliance/energy-codefield-studies). The data collected during Phase III will be made publicly available after the analysis is completed.

Table 2: Number of Homes Visited and Annual Permits.

\begin{tabular}{|c|c|c|c|}
\hline U.S. State & Phase I & Phase III & $\begin{array}{c}\text { Annual } \\
\text { Permits }\end{array}$ \\
\hline AL (Alabama) & 134 & 126 & 9,506 \\
\hline AR (Arkansas) & 166 & $a$ & 5,257 \\
\hline GA (Georgia) & 216 & $b$ & 27,503 \\
\hline KY (Kentucky) & 140 & 121 & 7,345 \\
\hline MD (Maryland) & 207 & 185 & 10,541 \\
\hline $\begin{array}{c}\text { NC (North } \\
\text { Carolina) }\end{array}$ & 249 & $b$ & 30,029 \\
\hline PA (Pennsylvania) & 171 & 160 & 16,371 \\
\hline TX (Texas) & 133 & $b$ & 100,609 \\
\hline
\end{tabular}

a: did not continue to Phase III.

$b$ : not completed yet.

\section{Prototype Model and EnergyPlus Simulation}

As described below, the data collected from single site visits to randomly selected homes under construction is applied to the residential building prototype model developed by PNNL for U.S. DOE's residential code analyses (Taylor, Mendon, and Fernandez, 2015).

\section{Simulation to Compare Baseline and Observed Energy Consumption}

It is assumed that the visited homes are a representative subset of new residential construction stock in the state, the data collected for key code items are empirical distributions of the code values expected in the time period when the field studies were conducted, and the distributions of the key code items are independent from each other. A bootstrap sampling process (Hesterberg, 2015) was used to generate combinations of the key code items by randomly drawing from each of their respective empirical distributions. Each combination of the randomly drawn values of all the key code items was treated as a plausible set of observations that could have been obtained from a newly constructed home in the state. Each set of the randomly drawn value combinations of the key code items was thus applied to the prototype model, a building model with all the necessary inputs, i.e., a pseudo-home, was thus created. Repeating the random process a large number of times ( $\mathrm{N}=1500$ in this study), a population of $\mathrm{N}$ pseudo-homes was thus created for each state. Altogether, the variations of the key code items in the $\mathrm{N}$ pseudo-homes follow the empirical distributions of the key code items observed from field survey. The set of $\mathrm{N}$ pseudo-homes thus reflects the current state of code compliance of new residential construction in a state. In order to evaluate the code compliance of the new residential construction represented by the $\mathrm{N}$ pseudohomes, a code compliant pseudo-home was created by setting the value of all key code items to the corresponding prescriptive and/or mandatory requirements of the code in effect in the state. This yields $\mathrm{N}+1$ total pseudo-homes.

The single-family residential building prototype models include five different foundation types (slab-on-grade, vented crawlspace, conditioned crawlspace, heated basement, unheated basement), and four different heating system types (gas furnace, electric resistance, heat pump, fuel oil furnace). Due to the different energy use impact of foundation type and heating system type, each of the $N$ +1 pseudo-homes was thus replicated into $M$ copies to account for the $M$ combinations of foundation type and heating system type. The $M$ replicates of a pseudo-home were otherwise identical to each other with respect to building construction, equipment, and internal loads. For states with multiple, say $K$, climate zones, the building model creation was repeated $K$ times leading to $K \times M \times$ $(N+1)$ total building models. The EnergyPlus simulations were conducted on an hourly basis and the annual energy use intensity (EUI) and energy costs were calculated from hourly outputs separated by fuel types for code regulated loads. The EUI of each pseudo-home was calculated by weighting the EUIs of the $M$ EnergyPlus models belonging to this pseudo-home based on their shares in the distributions. Table 3 lists the number of climate zones, $K$, the number of foundation types and heating system types, $\mathrm{M}$, the number of pseudo-homes, $N$, as well as the number of EnergyPlus simulation models for each of the eight states at Phase I. To retain consistency between the two phases as described in the next section, Phase III is subjected to the same number of models and EnergyPlus runs.

\section{Post-Stratified Sampling}

When we applied the methodology developed at Phase I for Phase III data, several issues arose.

First, the number of permits issued annually in a state varies from year to year. Since the methodology involved multiplying the average measure level savings per home by the number of permits to obtain the state level savings, 
it quickly became obvious that the state level savings was primarily driven by the number of permits. The methodology was thus revised to specify that the comparison of measure level savings was based on the Phase I number of permits.

Table 3: Number of Pseudo-homes and Simulation Runs.

\begin{tabular}{|c|c|c|c|c|c|}
\hline U.S. State & A & B & C & D & E \\
\hline AL & 2 & 4 & 3 & 3,002 & 36,024 \\
\hline AR & 2 & 2 & 2 & 3,002 & 12,008 \\
\hline GA & 3 & 5 & 2 & 4,503 & 45,030 \\
\hline KY & 1 & 4 & 3 & 1,501 & 18,012 \\
\hline MD & 1 & 4 & 3 & 1,501 & 18,012 \\
\hline NC & 2 & 5 & 3 & 3,002 & 45,030 \\
\hline PA & 2 & 3 & 2 & 3,002 & 18,012 \\
\hline TX & 4 & 1 & 3 & 6,004 & 18,012 \\
\hline
\end{tabular}

A: Number of Climate Zones, B: Number of Foundation Types, C: Number of Heating System Types, D: Number of Pseudohomes, E: Number of EnergyPlus Models for Main Simulation

The next issue was the distribution of heating system types, foundation types, and number of permits by climate zone. Because each of these distributions was used for weighting either the number of pseudo-homes or the results, changes in each of these distributions from Phase I to Phase III would skew the comparison. Therefore Phase I distributions were applied to the Phase III data analysis for consistency.

The third issue is the distribution of the number of observations by climate zone of individual key items differs between Phase I and Phase III in states with multiple climate zones. In the Monte Carlo process used to assign observations to individual building models, all observations of each key item within a state are pooled together. For states with multiple climate zones and for key items with varying code requirements among climate zones, the pooling may introduce abnormally high or low observations into a climate zone. When the distribution of key items by climate zone differs between Phase I and Phase III, randomly drawn observations from the pooled data for the state may lead to bias. In order to maintain consistency in random sample drawing between Phase I and Phase III, the key item distribution by climate zone of Phase I is used to guide the random sample draw in both Phase I and Phase III. Instead of drawing from the pooled data with equal probability, a post-stratified sampling proportional to the key item distribution by climate zone of Phase I is enforced. For each strata (i.e., the observations in each climate zone), each observation has equal probability to be drawn.

\section{Simulation for Measure Savings}

One goal of the Phase I analysis is to identify specific gaps in code compliance and highlight them during targeted training and outreach activities in Phase II. Another goal is to estimate the energy savings potential if code compliance is improved such that each key code item meets code. For Phase III, a similar measure level analysis is conducted and the comparison between the two phases will show if Phase II training, education and outreach is effective.
The analysis designed for evaluating measure level savings begins by comparing the observation of each key code item with the code requirement to determine if it meets the code requirement or not. If a key code item has a significant number of observations not meeting the code requirement, it is a to-be-improved candidate for the targeted training, education, and outreach activities for code compliance improvement. Here, significance is defined as more than $15 \%$ of observations not meeting the code requirement. For each to-be-improved code item, the worse than code requirement observations are pulled out, and the unique values and their occurrence percentages are calculated.

Two sets of building models were created for the simulations. One set of building models was created with each unique worse than code requirement value. Another set of building models was created by replacing the worse than code requirement values with the code compliant values. The various foundation types and heating system types were taken into consideration through replicate EnergyPlus model simulations. The energy consumption difference between these two sets of models represents the theoretical energy saving potential that can be achieved if the current worse than code requirement observation is improved to just meet the code requirement. The developed approach has already been applied to the Phase I data (Xie et al., 2018) and it has been applied to Phase III data of four states that completed the data collection. The measure level energy savings results between Phase I and Phase III will yield insights on the effectiveness of the training, education and outreach activities of Phase II. It should be pointed out that the saving potential estimated might be treated as a theoretical maximum because it does not take interaction effects into account such as the increased amount of heating needed in the winter when energy efficient lights are installed (see footnote 4 of DOE, 2018).

\section{Results}

This section presents the results of four states that have completed all three phases: Alabama, Kentucky, Maryland and Pennsylvania.

\section{State-wide Average Energy Consumption}

Table 4 compares the baseline (code compliant) EUI and average observed EUI for the four states at both Phase I and Phase III.

The initial U.S. DOE field study methodology was designed to detect an EUI difference of $14195 \mathrm{~kJ} / \mathrm{m}^{2}$-yr between Phases I and III. Any change in excess of that threshold would indicate that a statistically significant change had taken place.

The average observed EUI decrease for three of the four states ranges from 4\% in Alabama to $10 \%$ in Maryland. The absolute reduction in Kentucky and Maryland exceeds the threshold of $14195 \mathrm{~kJ} / \mathrm{m}^{2}-\mathrm{yr}$, indicating that there is significant reduction of the energy consumption from Phase I to Phase III in these two states. The observed average EUI in Alabama decreases from Phase I to Phase III but the difference is below the $14195 \mathrm{~kJ} / \mathrm{m}^{2}$ - 
yr threshold, so the result is inconclusive. In contrast, Pennsylvania presents a significant increase on average observed EUI from Phase I to Phase III.

While three of the four states show state-wide EUI reduction, the EUI increase for Pennsylvania deserves further study.

Table 4: Average State-wide Energy Use Intensity (EUI) $[\mathrm{kJ} / \mathrm{m} 2-y r]$.

\begin{tabular}{|c|c|c|c|c|c|}
\hline $\begin{array}{c}\text { U.S. } \\
\text { State }\end{array}$ & $\begin{array}{c}\text { Code } \\
\text { Complai } \\
\text { nt }\end{array}$ & Phase I & $\begin{array}{c}\text { Phase } \\
\text { III }\end{array}$ & $\begin{array}{c}\text { Differe } \\
\text { nce }\end{array}$ & $\begin{array}{c}\text { Chan } \\
\text { ge \% }\end{array}$ \\
\hline AL & 209,074 & 224,973 & 216,228 & 8,745 & $4 \%$ \\
\hline KY & 385,895 & 355,573 & 334,904 & 20,669 & $6 \%$ \\
\hline MD & 312,986 & 346,260 & 312,418 & 33,842 & $10 \%$ \\
\hline PA & 516,495 & 462,551 & 495,258 & $-32,707$ & $-7 \%$ \\
\hline
\end{tabular}

\section{Measure Level Saving Analysis}

Table 5 presents the measure level saving potential based on both Phase I and Phase III calculations.
The measure level saving potential is an indicator of how well homes performed compared to code-compliant homes. If all homes meet code, there is no saving potential. Therefore a reduction in savings potential indicates improvement in code compliance.

In the four states completed to date, the majority of key code items exhibit improvement, but not all code items follow such a trend. For Alabama and Maryland, improvement is shown in all to-be-improved code items identified at Phase I. A few code items show worse code compliance in Kentucky, but overall, the code compliance improved from Phase I to Phase III as indicated by its reduced saving potential. Pennsylvania shows a different trend. Half of the to-be-improved code items were improved, the other half got worse, and the overall code compliance became worse. The measure level results are consistent with the state-wide results shown in Table 4.

Table 5: Measure Level Annual Savings Potential (Phase III vs Phase I).

\begin{tabular}{|c|c|c|c|c|c|c|c|}
\hline \multirow[b]{2}{*}{ State } & \multirow[b]{2}{*}{ Key Code Items } & \multicolumn{3}{|c|}{ Total Energy Savings Potential (GJ) } & \multicolumn{3}{|c|}{ Total Cost Savings Potential (\$) } \\
\hline & & Phase I & Phase III & Reduction \% & Phase I & Phase III & Reduction \% \\
\hline \multirow{6}{*}{$\begin{array}{c}\text { AL } \\
(2015 \text { IECC) }\end{array}$} & Duct Leakage & 15,214 & 12,440 & $18.2 \%$ & $\$ 395,063$ & $\$ 323,238$ & $18.2 \%$ \\
\hline & Lighting & 11,492 & 8,663 & $24.6 \%$ & $\$ 385,451$ & $\$ 290,649$ & $24.6 \%$ \\
\hline & Envelope Air Leakage & 11,823 & 8,319 & $29.6 \%$ & $\$ 263,089$ & $\$ 185,084$ & $29.6 \%$ \\
\hline & Exterior Wall Insulation & 8,464 & 7,370 & $12.9 \%$ & $\$ 201,105$ & $\$ 175,080$ & $12.9 \%$ \\
\hline & Window SHGC & 1,381 & 102 & $92.6 \%$ & $\$ 54,674$ & $\$ 4,534$ & $91.7 \%$ \\
\hline & TOTAL & 48,373 & 36,895 & $23.7 \%$ & $\$ 1,299,381$ & $\$ 978,585$ & $24.7 \%$ \\
\hline \multirow{7}{*}{$\begin{array}{c}\text { KY } \\
(2009 \text { IECC) }\end{array}$} & Envelope Air Leakage & 28,679 & 613 & $97.9 \%$ & $\$ 484,314$ & $\$ 10,321$ & $97.9 \%$ \\
\hline & Ceiling Insulation & 11,999 & 5,103 & $57.5 \%$ & $\$ 215,656$ & $\$ 91,786$ & $57.4 \%$ \\
\hline & Exterior Wall Insulation & 9,788 & 8,699 & $11.1 \%$ & $\$ 171,044$ & $\$ 151,974$ & $11.1 \%$ \\
\hline & Foundation Insulation & 7,174 & 12,319 & $-71.7 \%$ & $\$ 108,156$ & $\$ 178,905$ & $-65.4 \%$ \\
\hline & Lighting & 6,058 & 4,704 & $22.3 \%$ & $\$ 197,544$ & $\$ 153,383$ & $22.4 \%$ \\
\hline & Duct Leakage & 2,253 & 18,101 & $-703.6 \%$ & $\$ 43,142$ & $\$ 342,217$ & $-693.2 \%$ \\
\hline & TOTAL & 65,951 & 49,540 & $24.9 \%$ & $\$ 1,219,858$ & $\$ 928,585$ & $23.9 \%$ \\
\hline \multirow{6}{*}{$\begin{array}{c}\text { MD } \\
(2015 \text { IECC) }\end{array}$} & Envelope Air Leakage & 56,834 & 14,687 & $74.2 \%$ & $\$ 754,946$ & $\$ 194,899$ & $74.2 \%$ \\
\hline & Wall Insulation & 26,619 & 4,846 & $81.8 \%$ & $\$ 401,480$ & $\$ 73,498$ & $81.7 \%$ \\
\hline & Lighting & 3,762 & 1,397 & $62.9 \%$ & $\$ 195,378$ & $\$ 24,595$ & $87.4 \%$ \\
\hline & Duct Leakage & 8,554 & 164 & $98.1 \%$ & $\$ 146,619$ & $\$ 8,115$ & $94.5 \%$ \\
\hline & Ceiling Insulation & 2,711 & 630 & $76.7 \%$ & $\$ 44,366$ & $\$ 10,307$ & $76.8 \%$ \\
\hline & TOTAL & 98,480 & 21,725 & $77.9 \%$ & $\$ 1,542,790$ & $\$ 311,414$ & $79.8 \%$ \\
\hline \multirow{7}{*}{$\begin{array}{c}\text { PA } \\
(2009 \text { IECC })\end{array}$} & Duct Leakage & 91,300 & 77,140 & $15.5 \%$ & $\$ 1,360,493$ & $\$ 1,160,783$ & $14.7 \%$ \\
\hline & Exterior Wall Insulation & 57,588 & 65,227 & $-13.3 \%$ & $\$ 798,031$ & $\$ 903,673$ & $-13.2 \%$ \\
\hline & Foundation Insulation & 18,689 & 3,539 & $81.1 \%$ & $\$ 175,676$ & $\$ 14,477$ & $91.8 \%$ \\
\hline & Lighting & 5,138 & 49 & $99.0 \%$ & $\$ 365,254$ & $\$ 41,178$ & $88.7 \%$ \\
\hline & Envelope Air Leakage & 6,624 & 41,081 & $-520.2 \%$ & $\$ 81,668$ & $\$ 506,777$ & $-520.5 \%$ \\
\hline & Ceiling Insulation & 33,576 & 60,114 & $-79.0 \%$ & $\$ 499,392$ & $\$ 893,386$ & $-78.9 \%$ \\
\hline & Total & 212,914 & 247,150 & $-16.1 \%$ & $\$ 3,280,515$ & $\$ 3,520,274$ & $-7.3 \%$ \\
\hline & & Phase I & Phase III & Change $\%$ & Phase I & Phase III & Change $\%$ \\
\hline All 4 states & Total & 425,718 & 355,309 & $16.5 \%$ & $\$ 7,342,543$ & $\$ 5,738,857$ & $21.8 \%$ \\
\hline
\end{tabular}

Figure 1 shows the distribution of the code items with the largest saving potential evaluated in Phase I for each state. The distribution indicates improvement and supports the measure level saving potential reduction from Phase I to Phase III. Figure 2 shows the distribution of a code item in each state with a reduction in saving potential from Phase I to Phase III. The improvement of the code item is also obvious. Figure 3 shows the distribution of a few code items in these states with an increase in saving potential from Phase I to Phase III. For ceilings in PA, the R-value of the insulation actually meets or exceeds the code requirement, however, poor insulation installation quality caused the inferior performance. In KY, a few very leaky homes in Phase III increase the saving potential from this code item. 
Although there was deteriorated code compliance in duct leakage and foundation insulation in $\mathrm{KY}$, overall $\mathrm{KY}$ has $\sim 24 \%$ saving potential reduction after Phase II activities. Considering the saving potential reduction in AL, KY, and $\mathrm{MD}$ and the saving potential increase in PA, the overall saving potential in the four states altogether was reduced by $17 \%$ of energy use and $22 \%$ of energy cost, suggesting the effectiveness of the Phase II training, education, and outreach activities.

\section{Discussion and Conclusions}

A consistent framework based on an energy metric has been established that can quantify gaps in code compliance and the effectiveness of compliance improving intervention strategies. This approach has recently been used by eight states. We evaluated the statewide average EUIs of new residential construction and individual code item measure level saving potential both before and after intervention activities such as education and training. We compared both the state-wide average EUI and the measure level saving potential of the four states that have completed all phases. The state-wide EUI results show significant EUI reductions in two states (KY and MD), inconclusive EUI reduction in AL, and EUI increase in PA. The measure level saving potential analysis shows that all to-be-improved code items identified in Phase I for AL and MD have been improved. Although the saving potential of two code items increase in $\mathrm{KY}$, the overall saving potential in KY decreased after Phase II. While the overall saving potential in PA increases, three code items show saving potential reduction after Phase II in PA. Table 5 indicates code compliance improvement after Phase II's education, training, and outreach activities. There was an overall improvement in three of the four states. In two of the four states every to-be-improved code item showed improvement, while in the other two states some code items improved while some got worse. Future study is needed specifically for those code items in the states showing deteriorated performance after the targeted education, training, and outreach activities.

\section{Acknowledgement}

The authors are grateful for research support provided by the Building Energy Codes Program (BECP) of U.S. DOE. The Pacific Northwest National Laboratory is operated for U.S. DOE by Battelle Memorial Institute under contract DE-AC05-76RL01830.

\section{References}

Bartlett, R., M. Halverson, J. Goins, and P. Cole (2016). "Commercial Building Energy Code Compliance Literature Review." Pacific Northwest National Laboratory (PNNL)-25218.

Bartlett, R., M. Halverson, V. Mendon, J. Hathaway, and Y.L. Xie (2018). Residential Energy Code Field Study: Data Collection and Analysis Methodology, PNNL-27009.

Crawley, D. B., L. K. Lawrie, F. C. Winkelmann, W. F. Buhl, Y.J. Huang, C. O. Pedersen, R. K. Strand, et al.
(2001). "EnergyPlus: Creating a New-Generation Building Energy Simulation Program." Energy and Buildings 33 (4): 319-331.

Deru, M., K. Field, D. Studer, K. Benne, B. Griffith, P. Torcellini, B. Liu, et al. (2011). "U.S. Department of Energy Commercial Reference Building Models of the National Building Stock." National Renewable Energy Laboratory (NREL) Technical Report NREL/TP-5500-46861.

Deru, M., K. Field, D. Studer, K. Benne, B. Griffith, P. Torcellini, B. Liu, et al. (2011). "U.S. Department of Energy Commercial Reference Building Models of the National Building Stock." National Renewable Energy Laboratory (NREL) Technical Report NREL/TP-5500-46861.

DOE (2018). Residential Energy Code Field Study - Data Collection and Analysis Methodology. Washington, DC. U.S. DOE. Available at https://www.energy.gov/sites/prod/files/2018/06/f52/ bto-Res-Field-Study-Methodology-060618-2.pdf.

FOA, Funding Opportunity Announcement, Strategies to Increase Residential Energy Code Compliance Rates and Measure Results, https://www.energycodes.gov/compliance/residentialenergy-code-field-study.

Fernandez, N., S. Katipamula, W. Wang, Y. L. Xie, and M. Zhao (2017). "Energy Savings Potential From Improved Building Controls for the U.S. Commercial Building Sector." Energy Efficiency 11 (2): 393-413. doi:10.1007/s12053-017-9569-5.

Halverson, M., V. Mendon, R. Bartlett, J. Hathaway, and Y. L. Xie (2015). "Residential Energy Code Sampling and Data Collection Guidance for Project Teams." Pacific Northwest National Laboratory (PNNL)23538.

Hesterberg, T.C. (2015). "What Teachers Should Know about the Bootstrap: Resampling in the Undergraduate Statistics Curriculum”. The American Statistician 69(4): 371-386.

Lee, Allen, and Dan Groshans (2013). "To Comply or Not to Comply-What is the Question?" Paper presented at the 2013 International Energy Program Evaluation Conference, Chicago, Illinois, August 13-15.

PNNL (Pacific Northwest National Laboratory) (2010). "Measuring State Energy Code Compliance." (PNNL)-19281.

Reinhart, C. F., and C. C. Davila (2016). "Urban Building Energy Modeling - A Review of a Nascent Field." Building and Environment 97: 196-202. doi:10.1016/j.buildenv.2015. 12.001.

Rosenberg, M., R. Hart, R. Athalye, J. Zhang, and D. Cohan (2016). Potential Energy Cost Savings from Increased Commercial Energy Code Compliance. 2016 ACEEE Summer Study on Energy Efficiency in Building. Pacific Grove, California, USA. 
Storm, P, D.Baylon, B. Hannas, J. Hogan (2016). "Commercial Code Evaluation Pilot Study Final Report". Ecotope, Inc. Seattle, WA.

Thornton, B. A., M. I. Rosenberg, E. E. Richman, W. Wang, Y. L. Xie, J. Zhang, H. Cho, V. V. Mendon, R. A. Athalye, and B. Liu (2011). "Achieving the $30 \%$ Goal: Energy and Cost Savings Analysis of ASHRAE Standard 90.1-2010.” Pacific Northwest National Laboratory (PNNL)-20405.

Taylor, Z. T., V. V. Mendon, and N. Fernandez (2015). Residential Energy Code Changes." Pacific Northwest National Laboratory (PNNL)-21294 Rev 1.

U.S. Census Bureau. "Building Permits Survey." Accessed December (2017). https://www.census.gov/construction/bps/.

U.S. EIA (Energy Information Administration) (2017). "Frequently Asked Questions." Accessed Dec. 2017. https://www.eia.gov/tools/faqs/faq.php?id=86\&t=1.
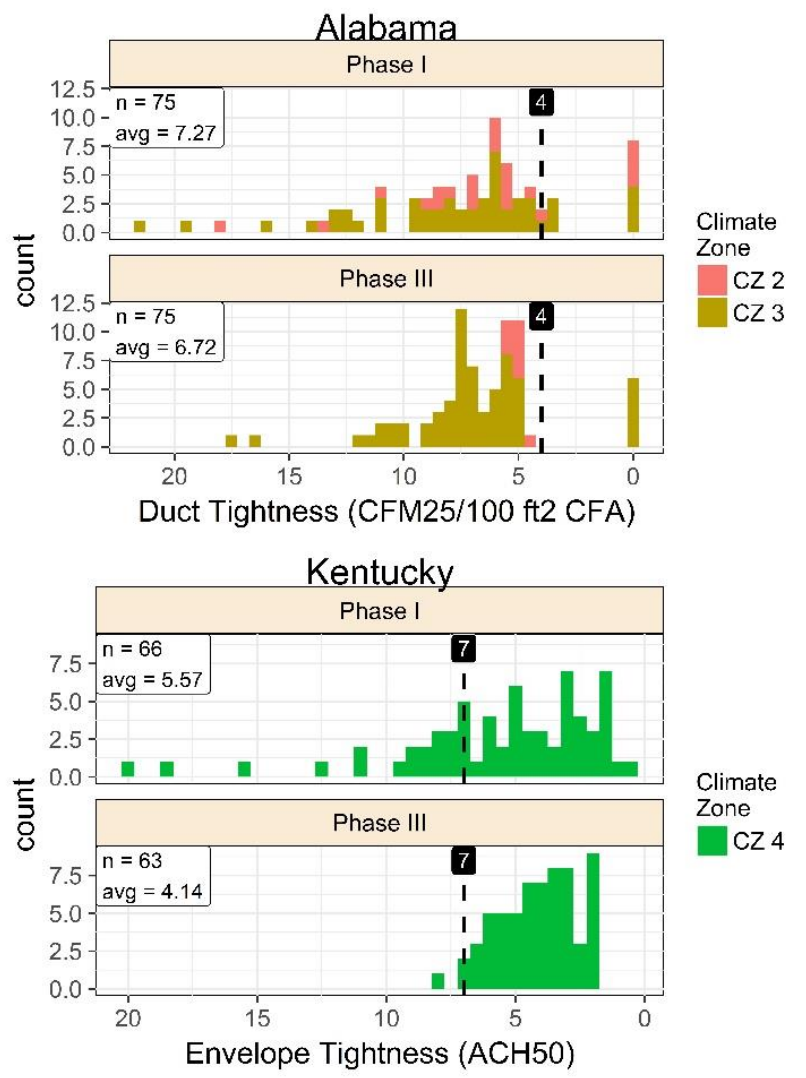
"Methodology for Evaluating Cost-Effectiveness of

Wang, L., S. Greenberg, J. Fiegel, A. Rubalcava, S. Earni, X. Pang, R. Yin, S. Woodworth, andJ. HernandezMaldonado (2013). "Monitoring-based HVAC Commissioning of an Existing Office Building for Energy Efficiency.” Applied Energy 102: 1382-1390.

Williams, J., C. David, M.A. Halverson, R. Bartlett, and Y.L. Xie (2018). Things Aren't As Bad (or Good) as They Seem: Lessons from the DOE Residential Energy Code Field Studies (2018) ACEEE Summer Study on Energy Efficiency in Building. Pacific Grove, California, USA.

Xie, Y.L., V.V. Mendon, M.A. Halverson, R. Bartlett, J.E. Hathaway, Y. Chen, M.I. Rosenberg, Z.T. Taylor and B. Liu (2018). Assessing Overall Building Energy Performance of a Large Population of Residential Single-Family Homes Using Limited Field Data. Journal of Building Performance Simulation (2018): 1-14.
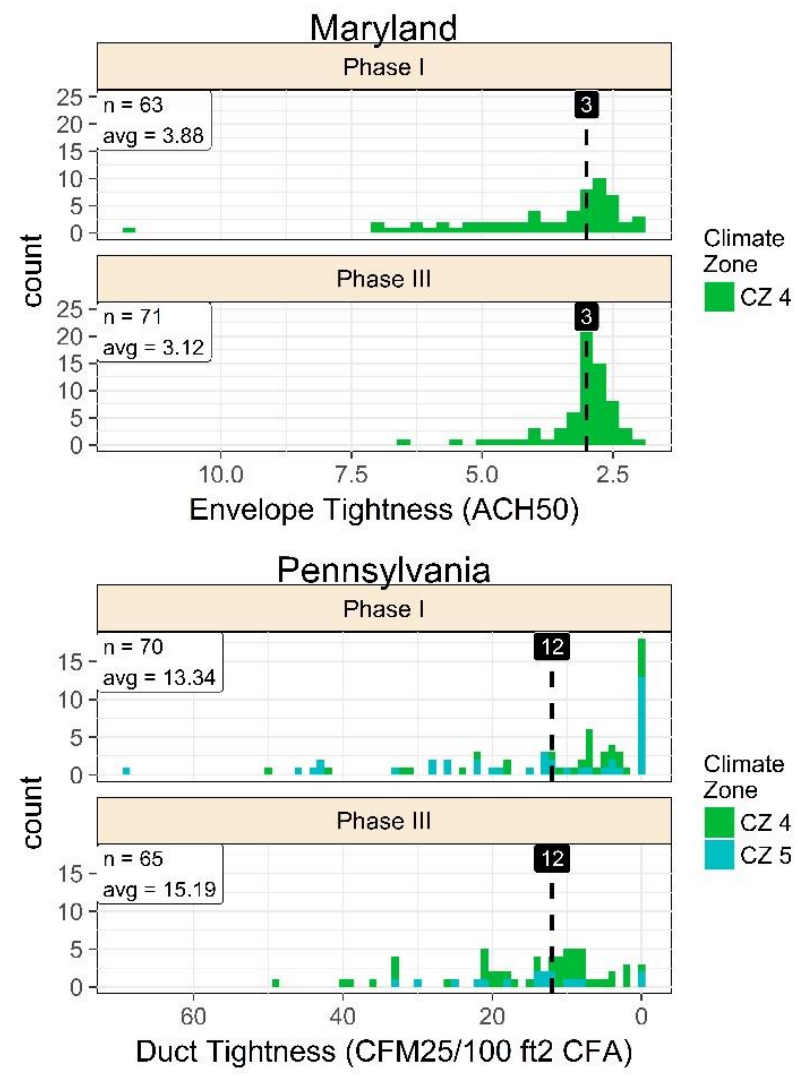

Figure 1: Observation Distributions of Code Items with the Largest Saving Potential Evaluated in Phase I by State. 

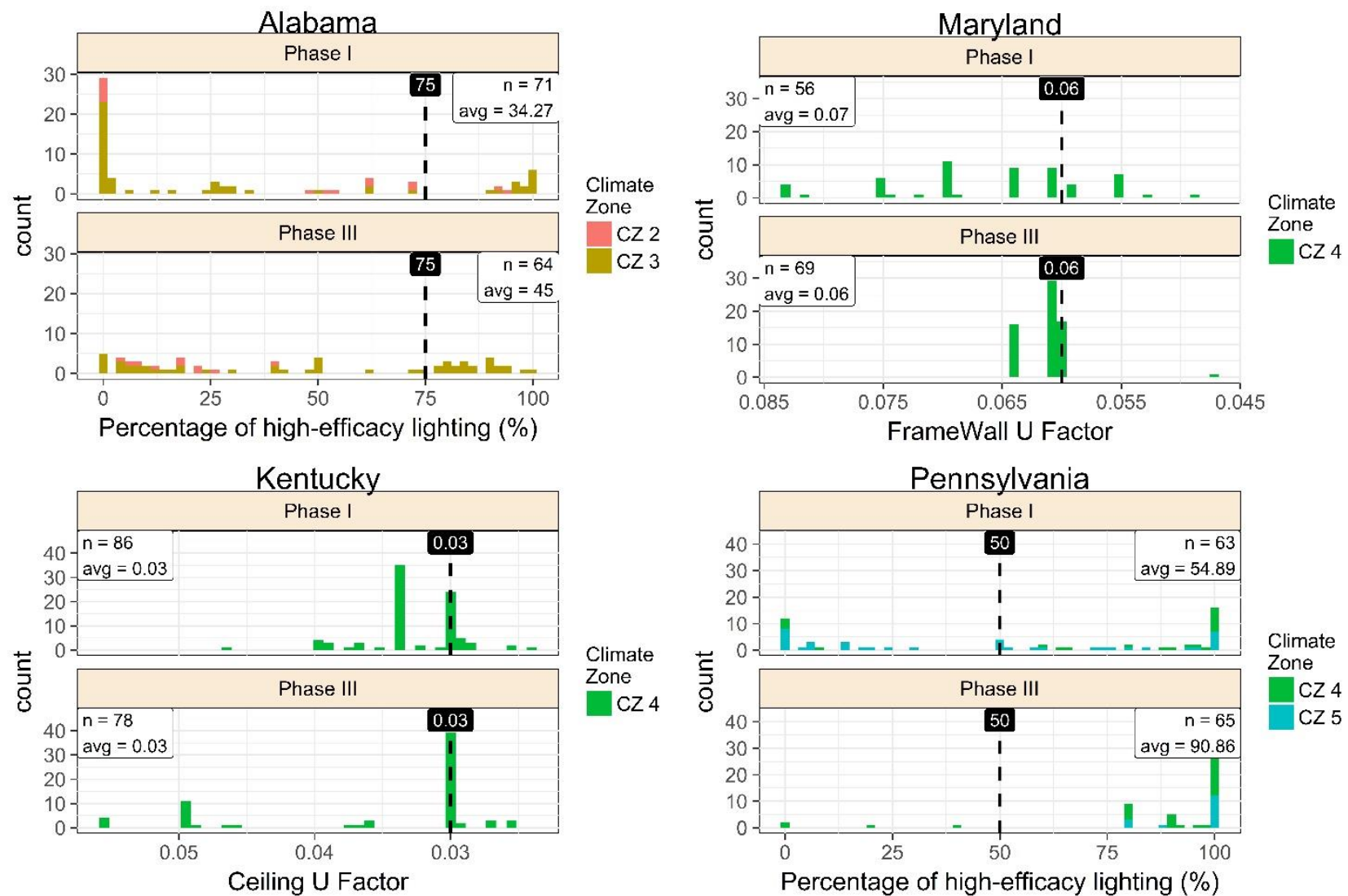

Figure 2: Observation Distributions of Code Items with a Reduction in Saving Potential from Phase I to Phase III by State.
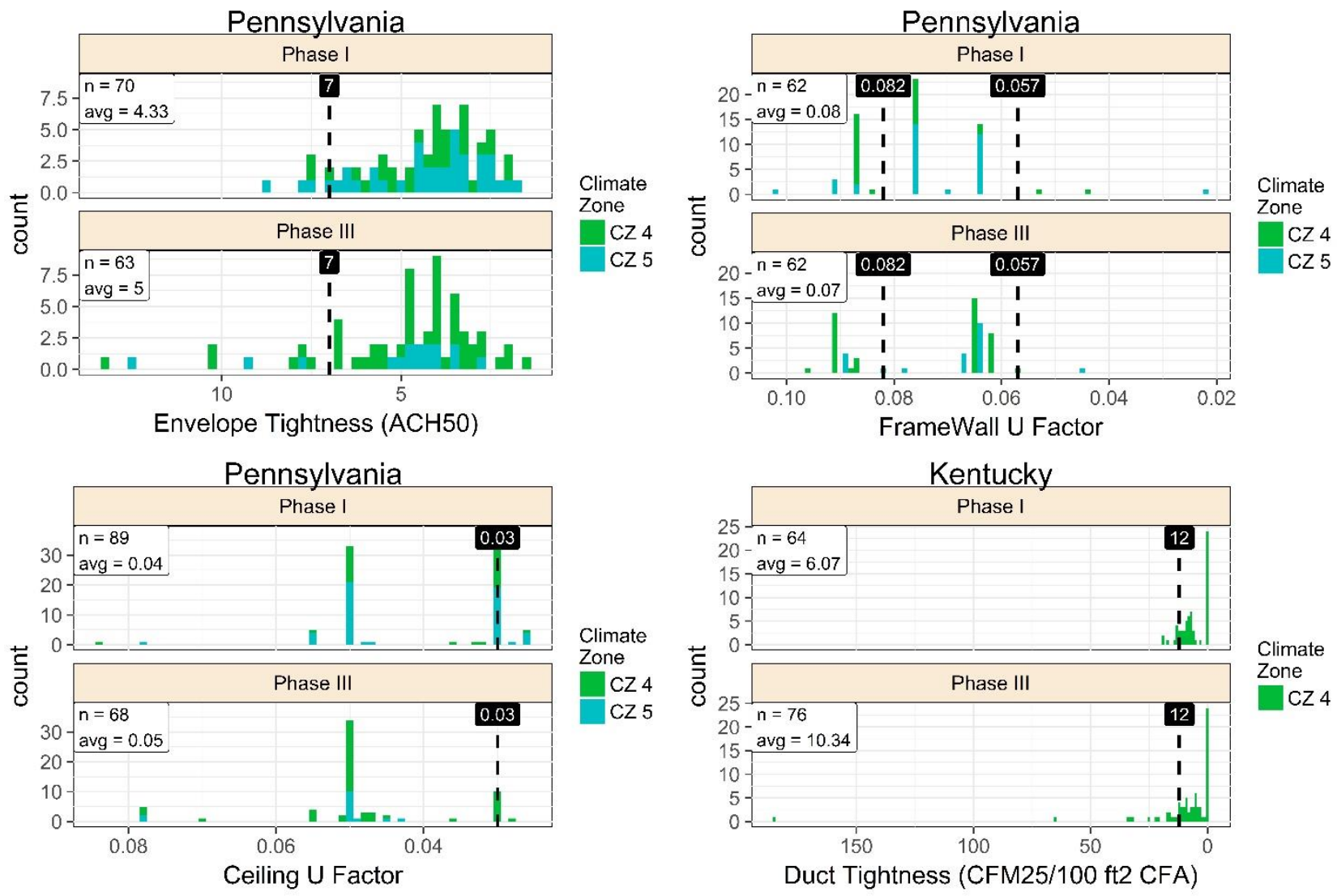

Figure 3: Observation Distributions of Example Code Items with an Increase in Saving Potential from Phase I to Phase III. 